\title{
Very High Cycle Fatigue Behavior of Ti-6Al-4V Alloy
}

\author{
$\mathrm{Nu} \mathrm{YAN}^{1,2}$, Xin ZHU ${ }^{1}$, Donggui HAN ${ }^{1}$, Fang LIU $^{1}$ \\ School of Mechanical Engineering \& Automation \\ Wuhan Textile University \\ Wuhan, China \\ e-mail: yannu@wtu.edu.cn
}

\author{
Yonghua $\mathrm{YU}^{2}$ \\ College of Mechanical \& Power Engineering \\ China three Gorges University \\ Yichang, China \\ e-mail: YuYongHuaCTGU@163.com
}

\begin{abstract}
In order to investigate the fatigue behavior of Titanium Alloy in very high cycle region, fatigue test of Ti-6Al$4 \mathrm{~V}$ was performed at ambient temperature by using ultrasonic fatigue equipment. Fracture surface morphology was observed by using Scanning Electron Microscope. The results demonstrate that the $\mathrm{S}-\mathrm{N}$ curve exhibited a continuously descending trend and the fatigue limit was not observed. The fatigue failure still occurred when the loading cycles exceeded $10^{8}$ cycles. Brittle failure and plastic failure were both observed under ultrasonic loading. Fatigue cracks in high cycles fatigue prefer to initiate from surface and in very high cycle fatigue the crack trend to initiate from subsurface.
\end{abstract}

Keywords-Ti-6Al-4V; Very high cycle fatigue; Crack initiation

\section{INTRODUCTION}

Titanium alloys exhibit excellent properties with lower density and higher strength, which play an important role in the aerospace industry where very high cycle fatigue is a common phenomenon [1]. When it is used to make the composer, it was required to exceed the lifetime of $10^{7}$ cycles. And ENSIP states that 'All engine parts should have a minimum VHCF life of $10^{9}$ cycles $^{[2]}$. So the design based on the lifetime of $10^{7}$ cycles is inadequate. Many researchers ${ }^{[3-7]}$ have studied the fatigue properties of titanium alloy and many significant conclusions were obtained. Ritchie ${ }^{[4]}$ discovered that different frequencies had little influence on the crack growth rate. But the failure mechanisms hadn't been discovered entirely. Hence, in order to discover the cracks initiate site, the authors performed the tests about the very high cycle fatigue of $\mathrm{Ti}$ $6 \mathrm{Al}-4 \mathrm{~V}$ and obtained the S-N curve. After which the fracture surfaces were examined.

\section{EXPERIMENTAL PROCEDURE}

\section{A. Materials}

The material used in the test was a titanium alloy Ti$6 \mathrm{Al}-4 \mathrm{~V}$, which is one of the most widely used titanium alloy. The titanium alloy Ti-6Al-4V was annealed at the temperature of $650^{\circ} \mathrm{C}$ for $1.5 \mathrm{~h}$. Mechanical properties of Ti$6 \mathrm{Al}-4 \mathrm{~V}$ under room temperature were determined to be $\mathrm{E}=110 \mathrm{GPa}, \sigma_{\mathrm{s}}=912 \mathrm{MPa}$ and $\sigma_{\mathrm{b}}=931 \mathrm{MPa}$, respectively. The chemical compositions (wt $\%$ ) were: $6.0 \mathrm{Al}, 4.0 \mathrm{~V}, 0.15 \mathrm{Fe}$, $0.10 \mathrm{C}, 0.01 \mathrm{~N}, 0.015 \mathrm{H}, 0.13 \mathrm{O}$ and rest $\mathrm{Ti}$.

\section{B. Specimen}

Fatigue test specimen was designed ${ }^{[8]}$ as the Figure 1 shown and polished by $1200 \#, 1500 \#$ abrasive papers after machined. The fatigue test was conducted by using Shimadzu ultrasonic test equipment at room temperature with loading frequency of $20 \mathrm{kHz}$ of and load ratio of $\mathrm{R}=-1$, respectively. If the frequency value varies outside the $19.5 \sim 20.5 \mathrm{kHz}$ the system shuts off automatically. In order to avoid the heating impact caused by high frequency, the specimen will be cooled down by compressed air when in experiment ${ }^{[9]}$. The fractured surfaces were reviewed by the SEM.

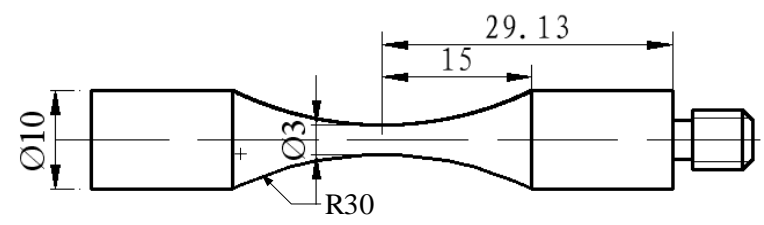

Figure 1. Shape and dimensions of the ultrasonic fatigue specimen.

\section{RESULT AND DISCUSSION}

\section{A. S-N curve}

The result showed that the $\mathrm{S}-\mathrm{N}$ curve declined continuously. There is not any obviously fatigue limit was founded. The fracture occurred even exceed $10^{8}$ cycles. Some researchers obtained similar S-N curves with stepwise in the fatigue test of other materials ${ }^{[10-11]}$. This phenomenon was originally observed in high strength steel and surface treatment steel ${ }^{[12-13]}$. Whether there are some relationships between the stepwise and fatigue limit haven't been discovered. The researches now are below $10^{10}$ cycles, whether there is fatigue limit out of $10^{10}$ cycles is not clear.

\section{B. Fracture surfaces analysis}

The fracture surfaces (a) the crack initiation close to the surface can be observed. The area near crack initiation is darker and more smoothly. There are numerous highlight stripes occurred in the area where close to the center of fracture. In picture (a) the remaining area of the crack expansion can be seen where lamellar tearing is clear to see.

From the picture (b) many river-like patterns can be observed. The surface is smoothly. It shows the failure mode is brittle failure. At the finishing area of the crack 
expanded. The river-like patterns are lighter and longer. This suggests that the failure mode is changing brittle failure into plastic failure. Therefore, we can figure out that the failure mode of the specimen consist of brittle failure and plastic failure.

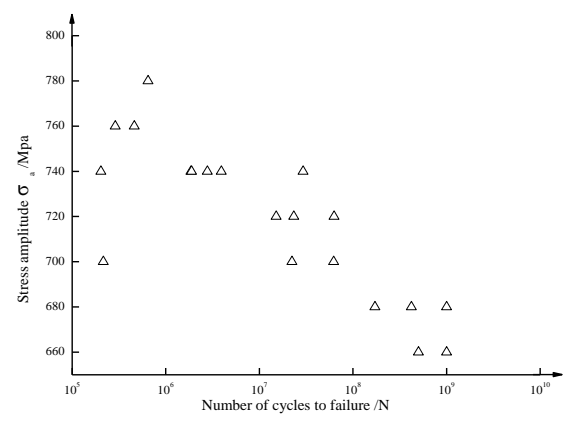

Figure 2. S-N curve of titanium alloy Ti-6Al-4V.

Some highlight primary alpha phases were founded as SEM picture(c) showed. The primary alpha phases are long platelets. It is clearer in picture (d).These long platelets will split base material and a decrease in mechanical properties of the base material. When crack initiated from the surface a accepted mechanism is about the formation of persistent slip band $^{[14]}$.

It was founded that all the cracks initiated from the surface. But another phenomenon was also founded that cracks prefer to initiate on the surface in the high cycle fatigue region and tend to initiate in the primary alpha phase just as Figure 4 showed, when cracks initiated from inside. It is widely believed that the crack initiate from internal inclusion in very abnormal cycle or abnormal grains etc. Ishii ${ }^{[15}$ performed push-pull fatigue test of $\mathrm{Cr} \mathrm{Mo}$ at $10^{5}-10^{8}$ cycles and founded that all the cracks initiated from internal inclusions. In very high cycle fatigue the crack is not initiated from internal inclusion but the metallurgical discontinuities such as planets. Some researchers have presented the mechanisms of where the cracks initiated from [16]. In high cycle fatigue the stress amplitude on the surface is brought up. The material on the surface is not difficult to yield plastic deformation. So the crack initiate from surface. However, when the stress amplitude is low, the crack is not able to initiate from surface. So the crack initiate from inclusion or abnormal grains and so on. In Ti-6Al-4V the crack initiated from the primary alpha phase which is long platelets shape. This primary alpha phase is not difficult to yield plastic deformation. So the crack initiated here.

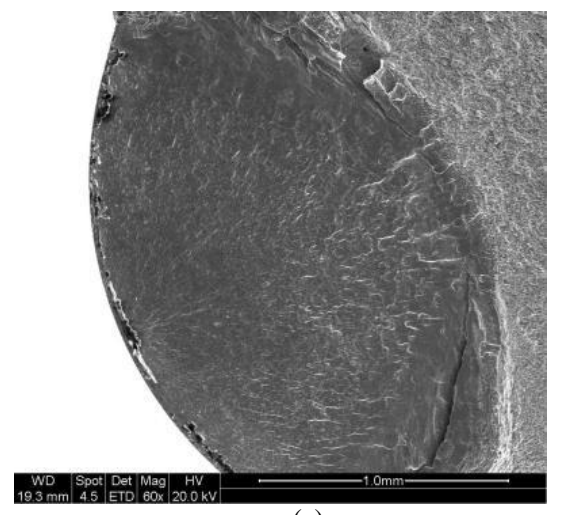

(a)

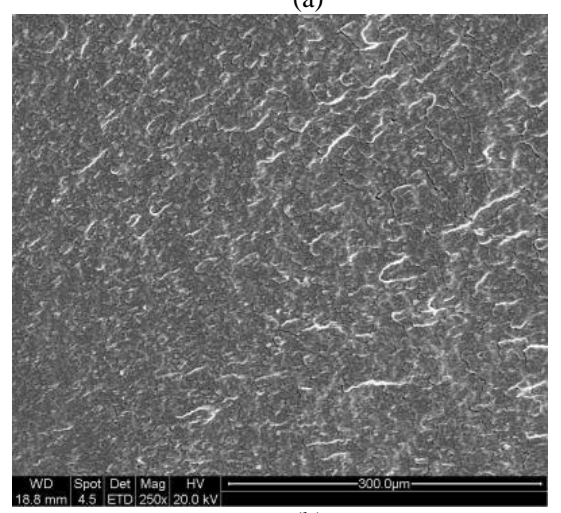

(b)

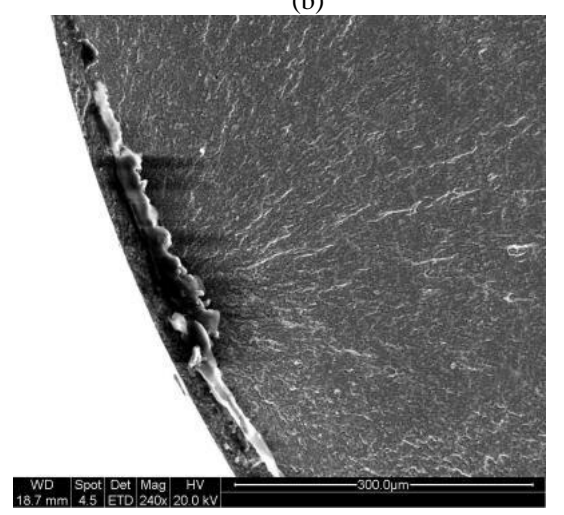

(c)

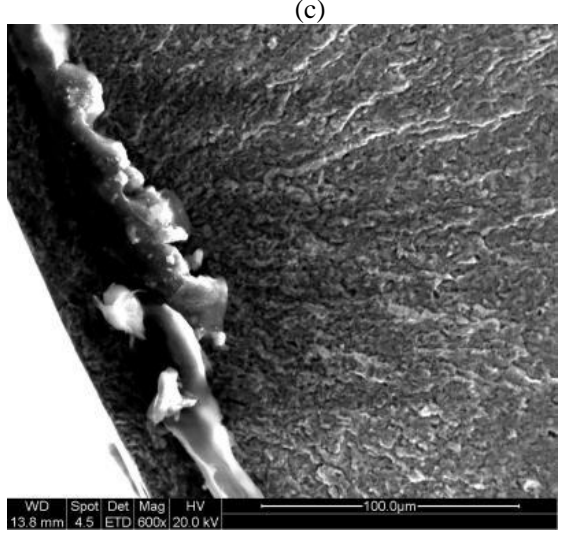

(d)

Figure 3. fracture morphology of the fatigue specimen with fatigue life of $5.01 \times 10^{8}$ cycles and cracks initiated from surface: (a) at low magnification and (b, c, d) magnified morphology. 


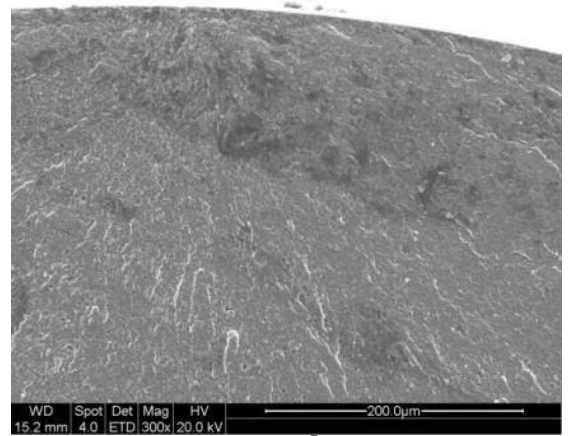

(a) $2.93 \times 10^{7}$ cycles

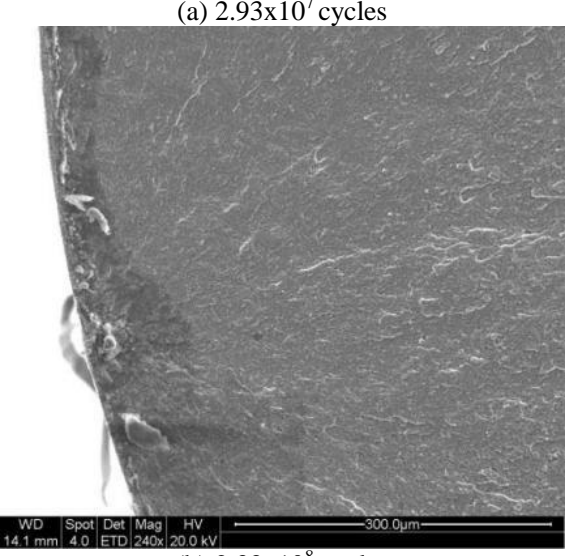

(b) $2.33 \times 10^{8}$ cycles

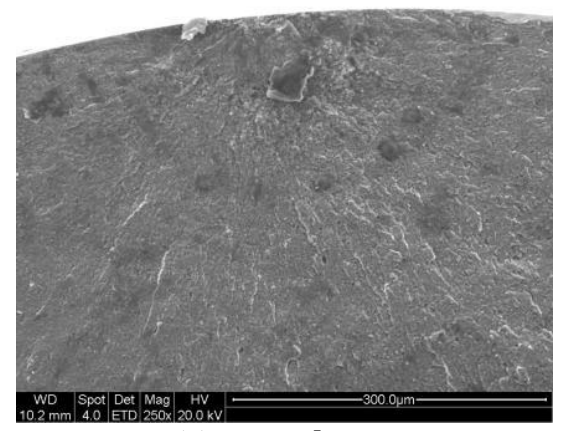

(c) $6.28 \times 10^{7}$ cycles

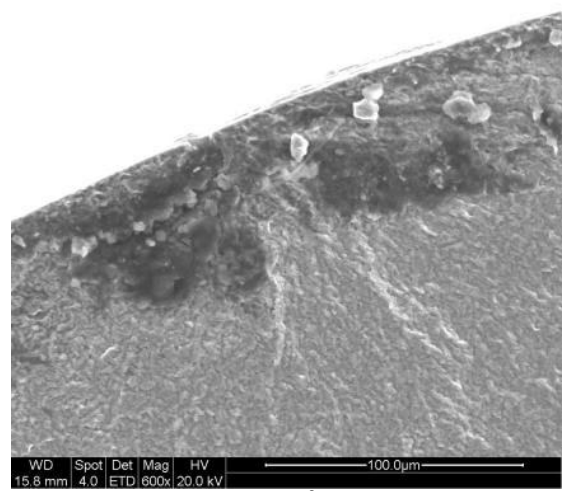

(d) $1.0 \times 10^{9}$ cycles

Figure 4. Fracture morphology of the failure specimens with fatigue life of $2.93 \times 10^{7}$ cycles and $2.33 \times 10^{8}$ cycles.

\section{CONCLUSIONS}

The very high cycle fatigue behavior of Ti-6Al-4V alloy was examined in detail. The results obtained in this study were as follows:

a) The S-N curve decrease continuously. There is no fatigue limit was founded in 109 cycles. The specimen fails still over 108 cycles.

b) During the failure process the failure mode of specimen is consist of brittle failure and plastic failure under ultrasonic loading.

c) In high cycle fatigue the cracks prefer to initiate on surface and in very high cycle it tends to initiate in Subsurface.

\section{ACKNOWLEDGMENT}

This work is supported by the National Natural Science Found of China (No.51175298) and Institutions of higher learning outstanding young scientific and technological innovation team of Hubei province (T201607).

\section{REFERENCES}

[1] V. fallah,S.F. Corbin,A. Khajepour, Process optimization of Ti-Nb alloy coatings on a Ti-6Al-4V plate using a fiber laser and blended elemental powders, J. Mater. Process. Technol.201(14)(2010) 20812087.

[2] ENSIP,Engine StructuralIntegrity Program Handbook,http://engineering.wpafb.af.mil/corpusa/handbook /mh1783/mh1783.pdf, rev.2002.

[3] Morrissey R J, Golden P J. Fatigue Strength of a Single Crystal in the Giga cycle Regime[J] International Journal of Fatigue, 200729(9-11): 2079-2084.

[4] Ritchie, Davidson, Boyce, et al. High-Cycle fatigue of Ti-6Al-4V [J]. Fatigue Fract. Engng. Mater. Struc, 1999, 22(7):621-631.

[5] CHAN K S. Roles of microstructure in fatigue crack initiation [J]. International Journal of Fatigue,010, 32:1428-1447.

[6] BANTOUNAS I, DYE D,LINDLEY T. The effect of grain orientation on fracture morphology during high-cycle fatigue of Ti6Al-4V[J]. Acta Materialia.2009, 57:3584-3595.

[7] BENEDETTIM,FONTANARI V. The effect of bi-modal and lamellar microstructure of Ti-6Al-4V on the behavior of fatigue cracks emanating from edge-notches [J]. Fatigue \& Fracture of Eng. Materials \& Structures,2004,27(3):1073-1089.

[8] Xue Hongqian, Tao Hua, Bathias C . The design of specimen for fatigue test at ultrasonic frequency[J]. Acta Aeronaut Et Astronaut Sinica, 2004,25(4);425(in Chinese)

[9] R.J. Morrissey. T.Nicholas. Fatigue strength of Ti-6Al-4V at very long lives[J]. International Journal of Fatigue, 27(2005),1608-1612.

[10] J.H. Zuo, Z.G. Wang, E.H. Han. Effect of microstructure on ultrahigh cycle fatigue behavior of $\mathrm{Ti}-6 \mathrm{Al}-4 \mathrm{~V}$. Materials Science and Engineering. Volume 473, Issues 1-2, 25 January 2008, Pages 147152

[11] Tanaka K, Akiniwa Y. Fatigue crack propagation behavior derived from S-N data in very high cycle regime. Fatigue Fract. Engng. Mater. Struct., 2002,25:775-784.

[12] Masuda C, Nishijima S, Tanaka Y. relationship between fatigue strength and hardness for high strength steels. Trans. JSEM, 1986, 52A:847 852.

[13] Naito T, Ueda H, Kikuchi M. Fatigue behavior of carburized steel with interal oxides and nonmartensitic microstructure near the surface. Metal Trans.1984, 15A:1431 1436. 
[14] Schijve J. Fatigue of structures and materials in the $20^{\text {th }}$ Century and the state of the art. International Journal of Fatigue, 2003,25:679 702.

[15] ISHII H,YAGASAKI T,AKAGI H.Evaluation of giga-cycle fatigue properties of some maraging steels by intermittent ultrasonic fatigue testing[J].Fatigue \& Fracture of Engineering Materials \& Structures, 2002,25(8/9):831-835.
[16] Miller K J. A historical perspective of the important parameters of metal fatigue; and problems for the next century. In: Wu X R, Wang $\mathrm{Z}$ G,eds. Proceedings of the $17^{\text {th }}$ International Fatigue Congress, Beijing,1999.15-39. 